\title{
EHLERS-DANLOS SYNDROME WITH SOFT-TISSUE CONTRACTURES
}

\author{
S. HAMADA, K. HIROSHIMA, S. OSHITA, T. DOI, K. ONO
}

\author{
From Osaka Rosai Hospital, Japan
}

\begin{abstract}
We report four patients with a form of Ehlers-Danlos syndrome associated with soft-tissue contractures from birth and skin hyperalgesia. In early infancy, these cases were thought to be forms of arthrogryposis multiplex congenita, Larsen's syndrome or Marfan's syndrome. The characteristic triad of signs of EhlersDanlos disease gradually appeared from four to six years of age, allowing us to establish the correct diagnosis. We discuss the differential diagnosis of these connective-tissue disorders and the problems of the orthopaedic treatment of the associated joint deformities. Ehlers-Danlos syndrome is a heterogeneous group of metabolic diseases of collagen and our cases constitute a group which is distinct from the conventional types.
\end{abstract}

Ehlers-Danlos syndrome (EDS) includes a heterogeneous group of inheritable disorders of collagen metabolism (McKusick 1972) presenting with the characteristic triad of joint hypermobility, hyperelasticity of the skin and fragility of the skin and blood vessels (Ronchese 1936). The spectrum of clinical symptoms is very wide: the mildest cases show only a slight deviation from normal, but the most severe have a life-threatening dysfunction of collagen tissue with various deformities which may lead to major disability (Macfarlane 1959; Beighton and Horan 1969; Hamada et al 1985, 1986; Kornberg and Aulicino 1985).

In 1985, Lewkonia and Pope first reported some patients with EDS who also suffered from joint contractures and acro-osteolysis. We discovered four patients with EDS who had soft-tissue contracture from birth and skin hyperalgesia. The coexistence of EDS and contracture complicates the clinical symptomatology, and may

S. Hamada, MD, Fellow

T. Doi, MD, Head of Orthopaedic Surgery

Department of Orthopaedic Surgery, Osaka Rosai Hospital, 1179-3, Nagasone-cho, Sakai-shi, Osaka 591, Japan.

K. Hiroshima, MD, Head of Orthopaedics

Division of Orthopaedics, Osaka National Hospital, 2-1-14 Houenzaka, Chuou-ku, Osaka 540, Japan.

S. Oshita, MD, Head of Orthopaedic Surgery

Minami-Osaka-Ryoikuen, Crippled Children Hospital, 5-26 Yamasaka-cho, Higashisumiyoshi-ku, Osaka 546, Japan.

K. Ono, MD, Professor and Chairman

Department of Orthopaedic Surgery, Osaka University Medical School, Fukushima-ku, Osaka 553, Japan.

Correspondence should be sent to Dr S. Hamada at 25-9, Naritahigashigaoka, Neyagawa-shi, Osaka 572, Japan.

(C) 1992 British Editorial Society of Bone and Joint Surgery 0301-620X/92/6406\$2.00

J Bone Joint Surg [Br] 1992: 74-B :902-5. result in misdiagnosis of arthrogryposis multiplex congenita, Marfan's syndrome or Larsen's syndrome.

We describe these four patients, and discuss the differe ! ial diagnosis and the problems of treating the associated joint deformities.

\section{PATIENTS}

From 1971 to 1989 , we diagnosed four patients as having EDS with associated soft-tissue contractures. There were three females and one male; their ages at first visit ranged from one month to 20 years and follow-up has been from two to 18 years (average nine years nine months) (Table I).

Three of these patients (cases 1,2 and 3) were first seen in infancy, with contractures, deformities and dislocations of their extremities, provisionally diagnosed as due to arthrogryposis multiplex congenita (AMC). The characteristic triad of EDS gradually appeared betw een the ages of four and six years, at which time the correct diagnosis was established. The fourth patient (case 4) was first seen at the age of 20 years, complaining of frequent wounds and subcutaneous haematomas after minor trauma. None of the patients had a history of congenital anomalies or musculoskeletal disorders in their family, but the parents of case 1 were consanguineous.

\section{CLINICAL FEATURES}

All four patients showed skin hyperelasticity and fragility. Using Carter and Wilkinson's (1964) method of assessment, they all had some degree of joint hypermo- 
bility. They bruised or bled easily after minor injury, and all had molluscoid pseudotumours (Ronchese 1936) and cigarette-paper scarring (McKusick 1972) of their limbs (Fig. 1).

Localised joint contractures, such as fixed congenital equinovarus deformity of the feet, were present from birth. Rubbing the skin caused hyperalgesia in all cases; this could not be established in early infancy, but was detected in all by the age of five years.

Three of the four patients had muscular hypotonia and one had Dandy-Walker syndrome with hydro- gradually improved without treatment during infancy. No patient had arachnodactyly.

Lower limb deformities. Congenital dislocation had occurred in four hips in three patients (cases 1, 2 and 4). Three hips were treated by a Pavlik harness in early infancy; the other (case 2) had an open reduction after failure of conservative treatment and later needed a derotation-varus osteotomy. Case 3 indicated multidirectional instability of the tibiofemoral joint resulting from soft-tissue laxity: no patient had congenital dislocation of the knee, often seen in Larsen's syndrome.

Table I. Four patients with EDS and soft-tissue contractures

\begin{tabular}{lllllll}
\hline & & & \multicolumn{3}{l}{ Signs of EDS } \\
\cline { 5 - 7 } Case & Sex & $\begin{array}{l}\text { Age } \\
\text { first seen }\end{array}$ & $\begin{array}{l}\text { Follow-up } \\
\text { (years) }\end{array}$ & $\begin{array}{l}\text { Joint* } \\
\text { hypermobility }\end{array}$ & $\begin{array}{l}\text { Skin } \\
\text { hyperelasticity }\end{array}$ & $\begin{array}{l}\text { Skin } \\
\text { fragility }\end{array}$ \\
\hline 1 & F & 1 month & 15 & $3 / 5$ & Moderate & Moderate \\
2 & M & 1 month & 18 & $2 / 5$ & Moderate & Moderate \\
3 & F & 6 years & 4 & $2 / 5$ & Mild & Mild \\
4 & F & 20 years & 2 & $2 / 5$ & Moderate & Moderate \\
\hline
\end{tabular}
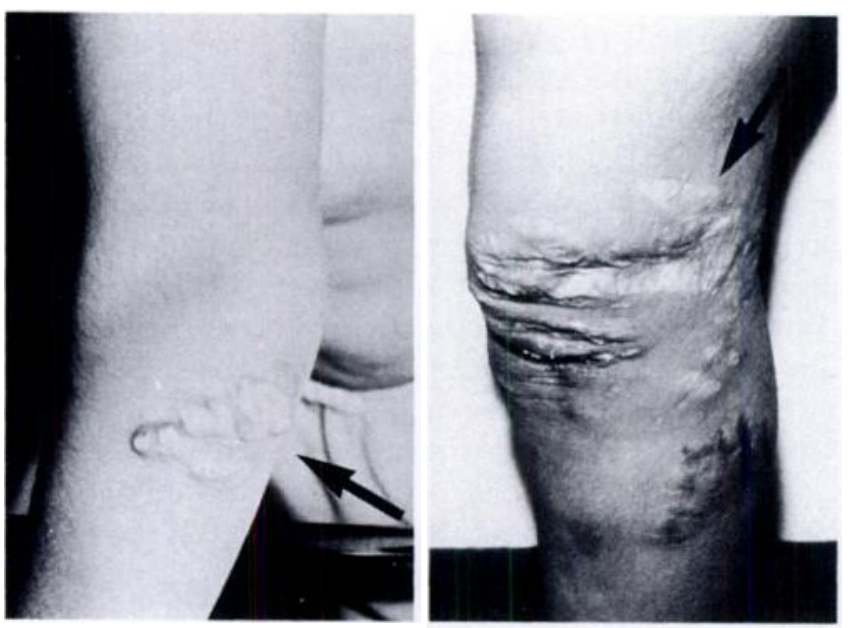

Fig. 1

Case I - Molluscoid pseudotumour at the elbow (left) and cigarettepaper scarring about the knee (right).

cephalus. All four had peculiar and similar facies, with broad and flat nasal bridges, hypertelorism and short skulls in the sagittal plane.

Upper limb deformities. Case 4 had swan-neck deformities of the fingers and case 1 had moderate contractures of the shoulder and elbow. Extension contractures of the fingers were seen in all patients, with the main restrictions at the MP and DIP joints (Fig. 2). These showed no spontaneous improvement during follow-up. Thumb-inpalm deformity was also seen in all patients, but this

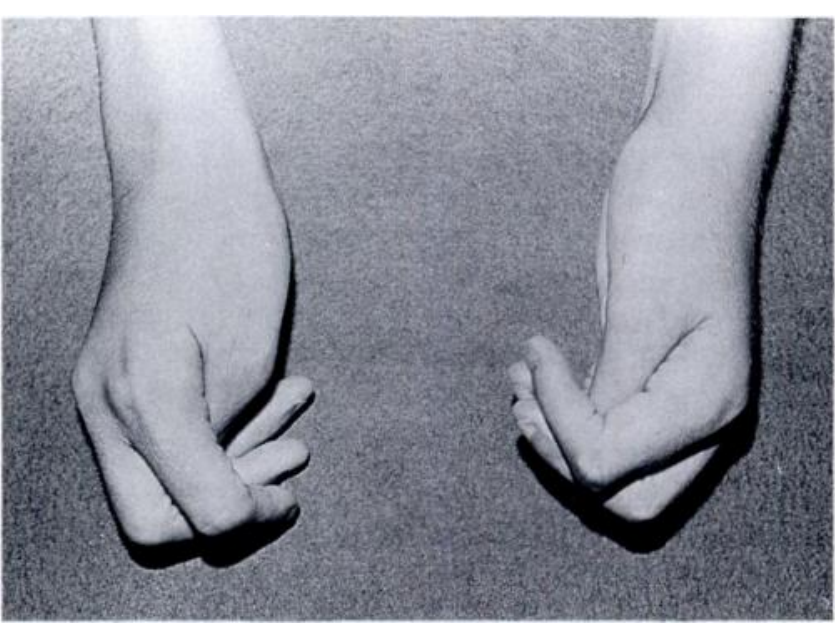

Fig. 2

Case 1 - Extension contracture of fingers at the metacarpophalangeal and distal interphalangeal joints.

Bilateral congenital equinovarus deformity in all cases (Fig. 3) failed to respond to manipulation and serial plasters: six feet (cases 1, 2 and 3) had surgical release, and two feet (case 4) were left untreated with severe deformity until first seen by us at the age of 20 years. The six operated feet all had multiple procedures. Incomplete release always resulted in an unsatisfactory, non-plantigrade foot but later drastic release procedures such as complete subtalar release caused marked valgus deformity. Three feet needed subsequent extra-articular subtalar 
arthrodesis and three had triple arthrodesis to obtain a plantigrade foot.

Traumatic dislocations. All four patients suffered traumatic dislocation of joints from minor forces. Squatting, stumbling or falling caused hip dislocation in two (cases 1 and 3), and swimming was responsible for dislocation of the shoulder in one (case 4). The elbow dislocated in one patient when he slipped and fell (case 2), and the patella dislocated in another when she simply turned around (case 1). All these dislocations occurred between the ages of seven and 12 years, and did not require general anaesthesia for reduction. After manual reduction, immobilisation for three weeks was satisfactory.

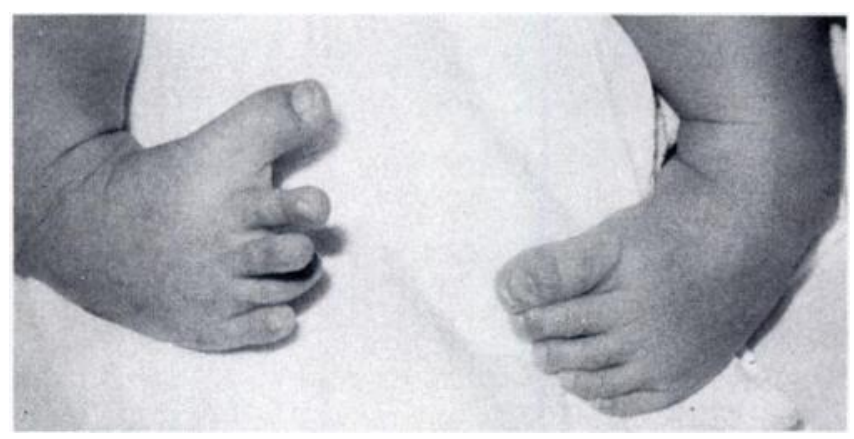

Fig. 3

Case 2 - Bilateral congenital club feet.

Other abnormalities. There was an ophthalmic abnormality in all cases: retinal ablation in one, optic nerve atrophy in one, and an accommodation disturbance in two. No patient showed dislocation of the lenses, which is present in about $70 \%$ of patients with Marfan's syndrome. One patient had a deformity of the thoracic cage, an inguinal hernia and muscular torticollis; one other had a scoliosis. None had any cardiovascular abnormalities.

Illustrative case report. Case 1. A Japanese girl with consanguineous parents was born by Caesarean section at 46 weeks' gestation. She had a peculiar face, congenital dislocation of the hip, bilateral club feet, contractures of the shoulder and elbow, and bilateral thumb-in-palm deformity. At one month, the provisional diagnosis of arthrogryposis multiplex congenita was made, although it was noted that her skin was slightly hyperelastic and her finger joints showed hyperlaxity despite extension contractures.

During the next four to five years, the triad of EDS gradually became more obvious, with repeated subcutaneous haematomas and the development of molluscoid pseudotumours and cigarette-paper scarring. Detailed physical examination showed severe skin hyperalgesia when the skin was rubbed, muscular hypotonia and muscle weakness. She suffered traumatic dislocation of the hip and of the patella as the result of minor trauma at the ages of seven and ten years respectively. At the age of 15 she has recurrent knee effusions caused by degenerative arthritis.

Her congenital dislocation of the hip was treated satisfactorily by a Pavlik harness but her club feet required repeated operations, culminating in triple arthrodesis at the age of 11 years.

\section{DISCUSSION}

Ehlers-Danlos syndrome has recently been divided into 11 types according to clinical manifestations, mode of inheritance and biochemical deficiencies (McKusick 1972). Our cases approximate to type II in some respects, but early diagnosis was impossible because of the existence of the contractures and skin hyperalgesia and the absence of the characteristic triad of EDS.

In early infancy our patients had some signs resembling those of AMC, Marfan's syndrome or Larsen's syndrome. Skin hyperelasticity and fragility are specific to EDS, however, and we did not observe the congenital knee dislocation, extra-ossicles at the extremities and peculiar flattened face characteristic of Larsen's syndrome. Moreover, in contrast with the gradual appearance of joint hypermobility at four or five years of age (Hamada et al 1986), which is characteristic of EDS, patients with Larsen's syndrome have a tendency to develop rigid joints during childhood (Houston, Reed and Desautels 1981).

Patients with Marfan's syndrome are tall and thin with arachnodactyly, a high arched palate, spinal scoliosis, dislocation of the lenses and cardiovascular involvement. These signs were rare in our patients. The easy bruising and tendency to haemorrhage after minor injury could cause confusion with child abuse, but the sites are different, being around joints in EDS and in inconspicuous or concealed regions in abused children.

EDS is a heterogeneous group of disorders of collagen metabolism, and it is therefore likely that further subgroups will be found: our series constitutes a group separate from the classical types of EDS. It is regrettable that we were unable to perform biochemical studies on cultured fibroblasts.

We have described several new signs: fixed deformities caused by soft-tissue contractures, hyperalgesia when the skin was rubbed, and various ophthalmic disorders. Lewkonia and Pope (1985) have reported joint contracture and acro-osteolysis in EDS, but the contractures were in EDS type IV patients, and involved peripheral joints in association with tight skin. Hamada et al (1986) have also reported progressive contractures about the ankle.

EDS patients with contractures need special attention before surgical correction is advised. Operation for club foot in early infancy, for example, requires complete correction of fixed and rigid deformities to obtain a plantigrade foot. A severely valgus foot may develop after surgery as a result of the laxity of the soft tissue 
which appears at the age of four or five years. This secondary deformity can be corrected only by bone surgery, such as a Grice-Green procedure or a triple arthrodesis.

No benefits in any form have been received or will be received from a commercial party related directly or indirectly to the subject of this article.

\section{REFERENCES}

Beighton P, Horan F. Orthopaedic aspects of Ehlers-Danlos syndrome. J Bone Joint Surg [Br] 1969; 51-B:444-53.

Carter C, Wilkinson J. Persistent joint laxity and congenital dislocation of the hip. J Bone Joint Surg [Br] 1964; 46-B:40-5.

Hamada $S$, Hiroshima $K$, Nakamura $M$, et al. Foot deformities in Ehlers-Danlos syndrome. Cent Jpn J Orthop Traumat 1985; 28:8446 (in Japanese).
Hamada S, Hiroshima $K$, Shibata $T$, et al. Ehlers-Danlos syndrome: clinico-pathology and orthopaedic treatment. J Jpn Orthop Assoc 1986; 60:1099-108 (in Japanese).

Houston CS, Reed MH, Desautels JEL. Separating Larsen syndrome from the 'Arthrogryposis basket'. J Canadian Assoc Radiol 1981; 32:206-14.

Kornberg M, Aulicino PL. Hand and wrist joint problems in patients with Ehlers-Danlos syndrome. J Hand Surg 1985; 10-A :193-6.

Lewkonia RM, Pope FM. Joint contractures and acro-osteolysis in Ehlers-Danlos syndrome type IV. J Rheumatol 1985; 12:140-4.

Macfarlane IL. Ehlers-Danlos syndrome presenting certain unusual features. J Bone Joint Surg [Br] 1959; 41-B:541-5.

McKusick VA. Heritable disorders of connective tissue. Fourth ed. St Louis: CV Mosby, 1972; 293-371.

Ronchese F. Dermatorrhexis with dermatochalasis and arthrochalasis (the so-called Ehlers-Danlos syndrome). Am J Dis Child 1936; $51: 1403-14$. 